\title{
Stability of Turoctocog Alfa, a Recombinant Factor VIII Product, during Continuous Infusion In Vitro
}

\author{
Masahiro Takeyama ${ }^{1}$ Anne Mette Nøhr ${ }^{2}$ Debra Pollard ${ }^{3}$ \\ ${ }^{1}$ Department of Pediatrics, Nara Medical University, Kashihara, Japan \\ 2 Novo Nordisk A/S, Biopharm Project Offices, Gentofte, Denmark \\ ${ }^{3}$ Katharine Dormandy Haemophilia and Thrombosis Centre, Royal \\ Free London NHS Foundation Trust, London, United Kingdom \\ Address for correspondence Anne Mette Nøhr, MSc, Novo Nordisk \\ A/S, Nybrovej 80, 2820 Gentofte, Denmark (e-mail: \\ amnq@novonordisk.com). \\ TH Open 2020;4:e354-e361.
}

\begin{abstract}
Keywords

- continuous infusion

- factor VIII

- hemophilia A

- potency

- stability

- turoctocog alfa

Objective Turoctocog alfa is a recombinant factor VIII (rFVIII) for the prevention and treatment of bleeding in patients with hemophilia $A$, including those undergoing surgery and invasive medical procedures. This in vitro study evaluated the physical and chemical stability of turoctocog alfa during continuous infusion $(\mathrm{Cl})$ over 24 hours at $30^{\circ} \mathrm{C}$.

Materials and Methods The study was performed at $30^{\circ} \mathrm{C}\left( \pm 2^{\circ} \mathrm{C}\right)$. A Cl system with pump speed set at either 0.6 or $1.5 \mathrm{~mL} / \mathrm{h}$ was used to evaluate the stability of three turoctocog alfa strengths $(500,1,000$, and $3,000 \mathrm{IU})$, equating to doses of 1.1 to 16.1 $\mathrm{IU} / \mathrm{h}$ per kilogram of body weight. The following parameters were evaluated at selected time points between 0 and 24 hours: appearance of solution, clarity, $\mathrm{pH}$, potency, purity, content, total high molecular weight proteins (HMWPs), and oxidized rFVIII.

Results The mean potency of turoctocog alfa was maintained within the predefined acceptance criteria during $\mathrm{Cl}$ for both pump speeds with all three strengths at 6,12 , or 24 hours (500 IU: $\geq 484 \mathrm{IU} /$ vial; 1,000 IU: $\geq 1,014 \mathrm{IU} /$ vial; and 3,000 IU: $\geq 3,029 \mathrm{IU} /$ vial). Furthermore, the appearance of solution, clarity, $\mathrm{pH}$, purity, content of turoctocog alfa, total HMWP, and oxidized forms were also within the predefined limits, and comparable to the reference samples (time $=0$ hours) for the pump speeds and product strengths assessed.

Conclusion Physical and chemical stability of turoctocog alfa was maintained during $\mathrm{Cl}$ over 24 hours. There was only minor degradation or changes in any of the parameters tested. Potency was within the prespecified acceptance limits throughout 24 hours of infusion. These findings confirm the suitability of turoctocog alfa for $\mathrm{Cl}$.
\end{abstract}

\section{Introduction}

Patients with hemophilia A may require major surgery, including elective orthopedic interventions due to chronic hemophilic arthropathy that develops following recurrent joint bleeds. ${ }^{1,2}$ To provide hemostatic control and protect

received

March 31, 2020

accepted after revision

September 23, 2020
DOI https://doi.org/

10.1055/s-0040-1719082. ISSN 2512-9465. against an increased risk of blood loss during major surgery, patients require peri- and postoperative correction of their low or missing factor VIII (FVIII) level by administration of a FVIII product. The World Federation of Hemophilia (WFH) guidelines suggest that FVIII concentrates should be infused by slow intravenous bolus injection at a maximum rate of

(c) 2020 Georg Thieme Verlag KG

Stuttgart · New York
License terms 
$3 \mathrm{~mL} / \mathrm{min}$ in adults and $100 \mathrm{IU} / \mathrm{min}$ in young children, or according to the manufacturer's guidelines. ${ }^{3}$

Continuous infusion $(\mathrm{Cl})$ is an alternative strategy that avoids FVIII concentration peaks and suboptimal troughs. ${ }^{3}$ The safety and efficacy of CI of FVIII for major surgery has been shown in a variety of studies, including for joint arthroplasties and synovectomies. ${ }^{4-9}$ Benefits of $\mathrm{Cl}$ over bolus injection of FVIII products, such as constant factor levels and reduced FVIII consumption, have also been demonstrated in patients with hemophilia in surgical settings. For example, a prospective controlled trial demonstrated less dangerous drops in FVIII levels and a 36\% reduction in total factor use for 13 days of treatment with $\mathrm{CI}$, compared with bolus FVIII infusions. ${ }^{4}$

A key requirement of FVIII concentrates for $\mathrm{CI}$ is that they are stable under the conditions of administration and over the duration of administration. Stability of various FVIII products have been evaluated under a range of storage conditions, including those usually encountered during CI. ${ }^{10-12}$ Continuous infusion administration techniques do, however, vary. ${ }^{13,14}$ In the hospital setting, infusion pump speeds of 0.4 to $1.5 \mathrm{~mL} / \mathrm{h}$ have been used to achieve doses of 1 to $10 \mathrm{IU} / \mathrm{h} / \mathrm{kg}$ of body weight. ${ }^{13-15}$

Turoctocog alfa (NovoEight, Novo Nordisk A/S, Bagsværd, Denmark) is a recombinant FVIII (rFVIII) product with a truncated B domain, for the prophylaxis and treatment of bleeds, and for use during surgery in patients with hemophilia $\mathrm{A}$; it is available in six strengths ranging from 250 to 3,000 IU/vial. ${ }^{16-20}$ Turoctocog alfa has been shown to be stable when stored at high temperature and high humidity. ${ }^{11,21}$ In addition, under conditions similar to those encountered during $\mathrm{Cl}$, reconstituted samples of turoctocog alfa were stable and retained $>83 \%$ of activity after 24 hours at $30^{\circ} \mathrm{C} .{ }^{21}$ The aim of this in vitro study was to evaluate the physical and chemical stability of reconstituted turoctocog alfa at a range of concentrations, and at high- and low-pump speeds over 24 hours $\mathrm{Cl}$ at $30^{\circ} \mathrm{C}$.

\section{Materials and Methods}

\section{Continuous Infusion Test System}

The CI test system comprised a BD Medical Plastipak 50-mL sterile polypropylene Luer-Lok syringe (Becton Dickinson \& Company Ltd., Drogheda, Ireland) attached to a $200-\mathrm{cm}$ standard polyethylene Original-Perfusor line Luer-Lok (B Braun, Melsungen AG, Melsungen, Germany), connected to a Perfusor Space automatic infusion pump (B Braun). There was no pretreatment of syringes or infusion tubes. Samples were collected in Immuno Tubes MiniSorp (Thermo Fisher Scientific, Waltham, Massachusetts, United States) and immediately stored at $-80^{\circ} \mathrm{C}$ until analysis.

\section{Sample Preparation and Analytical Setup}

The following two experiments were conducted: (1) one each at a pump speed of 1.5 and $0.6 \mathrm{~mL} / \mathrm{h}$. For each experiment, the required number of turoctocog alfa vials were reconstituted separately and pooled. The reconstituted drug product was not protected from direct light. Turoctocog alfa
Table 1 Turoctocog alfa dosages evaluated in study

\begin{tabular}{|l|l|l|}
\hline $\begin{array}{l}\text { Turoctocog alfa } \\
\text { vial strength } \\
\text { (strength } \\
\text { postreconstitution) }\end{array}$ & Calculation $^{\mathrm{a}}$ & $\begin{array}{l}\text { Study } \\
\text { dosage } \\
\text { (IU/h/kg } \\
\text { of BW) }\end{array}$ \\
\hline $\begin{array}{l}500 \mathrm{IU} \\
(125 \mathrm{IU} / \mathrm{mL})\end{array}$ & $125 \mathrm{IU} / \mathrm{mL} \times 0.6 \mathrm{~mL} / \mathrm{h} / \mathrm{BW}$ & 1.1 \\
\cline { 2 - 3 } $\begin{array}{l}1,000 \mathrm{IU} \\
(250 \mathrm{IU} / \mathrm{mL})\end{array}$ & $125 \mathrm{IU} / \mathrm{mL} \times 1.5 \mathrm{~mL} / \mathrm{h} / \mathrm{BW}$ & 2.7 \\
\cline { 2 - 3 } & $250 \mathrm{IU} / \mathrm{mL} \times 0.6 \mathrm{~mL} / \mathrm{h} / \mathrm{BW}$ & 2.1 \\
\hline $\begin{array}{l}3,000 \mathrm{IU} \\
(750 \mathrm{IU} / \mathrm{mL})\end{array}$ & $750 \mathrm{IU} / \mathrm{mL} \times 1.5 \mathrm{~mL} / \mathrm{h} / \mathrm{BW}$ & 5.4 \\
\cline { 2 - 3 } & $750 \mathrm{IU} / \mathrm{mL} \times 0.6 \mathrm{~mL} / \mathrm{h} / \mathrm{BW}$ & 6.4 \\
\hline
\end{tabular}

Abbreviation: BW, body weight.

aBW estimated at $70 \mathrm{~kg}$.

was reconstituted to $4.3 \mathrm{~mL}$ using a $5-\mathrm{mL}$ syringe with $0.9 \%$ sodium chloride, according to the manufacturer's recommendations. ${ }^{17}$ Since the manufacturer recommends using reconstituted turoctocog alfa within 24 hours if stored at 2 to $8^{\circ} \mathrm{C}$ or 4 hours if stored at $\leq 30^{\circ} \mathrm{C},{ }^{17}$ stability was assessed over 24 hours of $\mathrm{CI}$ at $30^{\circ} \mathrm{C}$. For each experiment, three vial strengths of turoctocog alfa were evaluated $(500,1,000$, and $3,000 \mathrm{IU}$, equating to concentrations of 125,250 , and 750 $\mathrm{IU} / \mathrm{mL}$ ) using identical pumps and test systems. For the pump speeds assessed, this equated to turoctocog alfa doses of 1.1 to $16.1 \mathrm{IU} / \mathrm{h} / \mathrm{kg}$ body weight (using a standardized body weight of $70 \mathrm{~kg}$; - Table $\mathbf{1}$ ).

For both pump speeds assessed, samples during $\mathrm{CI}$ were taken for up to 24 hours. Under aseptic conditions in both experiments, sterile syringes were filled with reconstituted turoctocog alfa that connected to an Original-Perfusor Line and then mounted in the infusion pump. At time point 0 hours, a manual bolus sample was taken immediately after the syringe/tube was filled. During CI, samples were collected at 6 hours (range: $0-6$ hours), 12 hours (range: $6-12$ hours), and 24 hours (range: $12-24$ hours). The experiments at different pump speeds were conducted on different days. The study was performed at $30^{\circ} \mathrm{C}\left( \pm 2^{\circ} \mathrm{C}\right)$, and samples were stored at $-80^{\circ} \mathrm{C}$ until analysis.

\section{Analyses}

The study was performed according to International Council for Harmonisation guidelines. ${ }^{22}$ The parameters reported were those from the drug product specification, as these are known to be parameters that indicate stability and are susceptible to change during $\mathrm{Cl}$ at $30^{\circ} \mathrm{C}$ and/or those likely to influence product quality. Unless stated otherwise, the samples at each time point were pooled and evaluated against a reference sample (time $=0$ hour). The results from the analyses below were calculated using appropriate statistical methods ${ }^{22}$; potency was analyzed using PLA 3.0 software (Stegmann Systems GmbH, Rodgau, Germany) and Microsoft Excel (Microsoft, Redmond, Washington, United States); results were visualized and validated using JMP Statistical Software (SAS Institute Inc., Cary, North Carolina, United States). 


\section{Appearance/Clarity of Solution}

The syringe, infusion tube, and turoctocog alfa solution were visually evaluated at 0 and 24 hours. ${ }^{23}$ The appearance was considered unchanged at 24 hours if the syringe, infusion tube, and reconstituted turoctocog alfa drug product did not show changes in transparency, color, sedimentation, presence of foreign insoluble matter, or other changes, when compared with the visual description at 0 hours.

\section{pH}

The $\mathrm{pH}$ of the samples was assessed at 0 and 24 hours according to the following country-specific standards: European Pharmacopoeia (section 2.2.3), U.S. Pharmacopeia (section 791), and Japanese Pharmacopeia (section 2.54) $\mathrm{pH}$ determination. $^{24-26}$

\section{Potency}

Potency was investigated using the chromogenic kit Coamatic FVIII (Chromogenix, Instrumentation Laboratory, Bedford, Massachusetts, United States) on the ACL Elite Pro analyzer (Instrumentation Laboratory), in accordance with European Pharmacopoeia Assay of human coagulation FVIII using a product-specific standard as calibrator. ${ }^{27}$ A productspecific standard (reconstituted in $0.9 \%$ sodium chloride) and turoctocog alfa samples from the test systems underwent the following three dilution steps: (1) predilution to approximately $11 \mathrm{IU} / \mathrm{mL}$ using buffer solution from the Coamatic FVIII kit; (2) dilution to approximately $1 \mathrm{IU} / \mathrm{mL}$ using FVIIIdeficient plasma; (3) dilution to approximately $0.005 \mathrm{IU} / \mathrm{mL}$ using the Coamatic FVIII kit buffer solution. Blank samples were prepared by dilution of $20-\mu \mathrm{L}$ FVIII-deficient plasma with $4,000-\mu \mathrm{L}$ buffer solution.

The test samples (together with the calibrator and blank samples) were analyzed in triplicate on the ACL Elite Pro analyzer. This resulted in a total of six results for each time point. Absorbance readings for test samples and calibrator were used to calculate potency using a slope-ratio analysis. Potency at each time point was deemed acceptable if the mean potency (of all six results) for the test samples did not deviate by more than $20 \%$ of the mean potency of the reference sample (sample taken at 0 hours), in accordance with data obtained in similar studies. ${ }^{28}$

\section{Purity}

The purity of turoctocog alfa samples was assessed using reverse-phase high performance liquid chromatography (RPHPLC). Analysis was performed on an HPLC system equipped with processing software and a $4.0 \mathrm{~mm} \times 250 \mathrm{~mm}, \mathrm{C} 4,5 \mu \mathrm{m}$, and 300-Å column (Novo Nordisk Pharmatech A/S, Køge, Denmark). The column temperature was set at $40^{\circ} \mathrm{C}$, with a detection wavelength of $215 \mathrm{~nm}$. A gradient of 35 to $100 \%$ eluent $B(0.09 \%$ trifluoracetic acid [TFA] in $80 \%$ acetonitrile in purified water) and 65 to $0 \%$ eluent A (0.1\% TFA in purified water) was applied over a 40-minute period with a flow rate of $1 \mathrm{~mL} / \mathrm{min}$. The composition of $100 \%$ eluent $B$ was then maintained for 5 minutes, before being changed back to the initial conditions over 1 minute, followed by column equilibration for 14 minutes, resulting in a total run time of 60 minutes.
The purity of turoctocog alfa was calculated as the sum of area percentages of the following components on the resulting chromatograms: turoctocog alfa light chain, turoctocog alfa single chain, and three heavy-chain $(\mathrm{HC})$ components (nontruncated form, one with the C-terminal at amino acid 740 [HC_740], and one with the C-terminal at amino acid 720 [HC_720]).

\section{Oxidized Forms}

Oxidized forms within the turoctocog alfa samples were assessed using the same RP-HPLC system, column, HPLC parameters (column temperature, detection wavelength, and mobile phase eluents), and elution gradients as those used to assess product purity. Oxidized forms were calculated as the percentage area on the resulting chromatograms.

\section{Total High Molecular Weight Proteins and Content of Turoctocog Alfa}

Samples were analyzed by size exclusion-HPLC (SE-HPLC) to determine the presence of protein aggregates and of turoctocog alfa in the samples. SE-HPLC measurements were performed using an HPLC system equipped with a BioSep SEC S3000 $7.8 \mathrm{~mm} \times 300 \mathrm{~mm}, 5 \mu \mathrm{m}, 290-\AA$ column (Phenomenex, Torrance, California, United States), or a Shodex PROTEIN KW$803.8 \mathrm{~mm} \times 300 \mathrm{~mm}$ column (Shodex, Showa Denko, Japan), or equivalent. An elution flow rate of $0.4 \mathrm{~mL} / \mathrm{min}$ was employed, using a column temperature of $30^{\circ} \mathrm{C}$ and excitation and emission detection wavelengths of 285 and $335 \mathrm{~nm}$, respectively. The eluent buffer consisted of $10 \mathrm{mM}$ TRIS, $10 \mathrm{mM} \mathrm{CaCl}_{2}, 300 \mathrm{mM}$ $\mathrm{NaCl}$, and 5\%2-propanol at $\mathrm{pH} 7.0$, and the injection volume was $100 \mu \mathrm{L}$, independent of protein concentration. Run times were $\geq 70$ minutes. Total HMWP content was determined by calculating the area percentage of the HMWP peak on the resulting chromatogram. The content of turoctocog alfa was calculated from the area of the monomer peak, relative to the average monomer peak area from the five injections of the reference material (a one-point calibration).

\section{Results}

\section{Appearance/Clarity of Solution and pH}

There were no changes in clarity, color, or the appearance of foreign insoluble matter compared with the visual description at study start for any vial strengths or pump speeds evaluated. All samples complied with the acceptance criteria on visual inspection: each reconstituted sample appeared as a clear or slightly opalescent solution. At 24 hours, $\mathrm{pH}$ had not changed and remained at 6.8 for all samples.

\section{Potency}

At $t=0$ hours, the mean potency (IU/vial) was: 491.6 for 500 IU, $1,108.0$ for $1,000 \mathrm{IU}$, and $3,139.5$ for $3,000 \mathrm{IU}$. The potency of turoctocog alfa was retained during 24 hours of $\mathrm{Cl}$ for all vial strengths and both infusion speeds evaluated ( - Fig. 1). Furthermore, the potency results for the test samples were all within the predefined acceptance criteria (within $20 \%$ of the mean potency of the $t=0$ hours sample). 


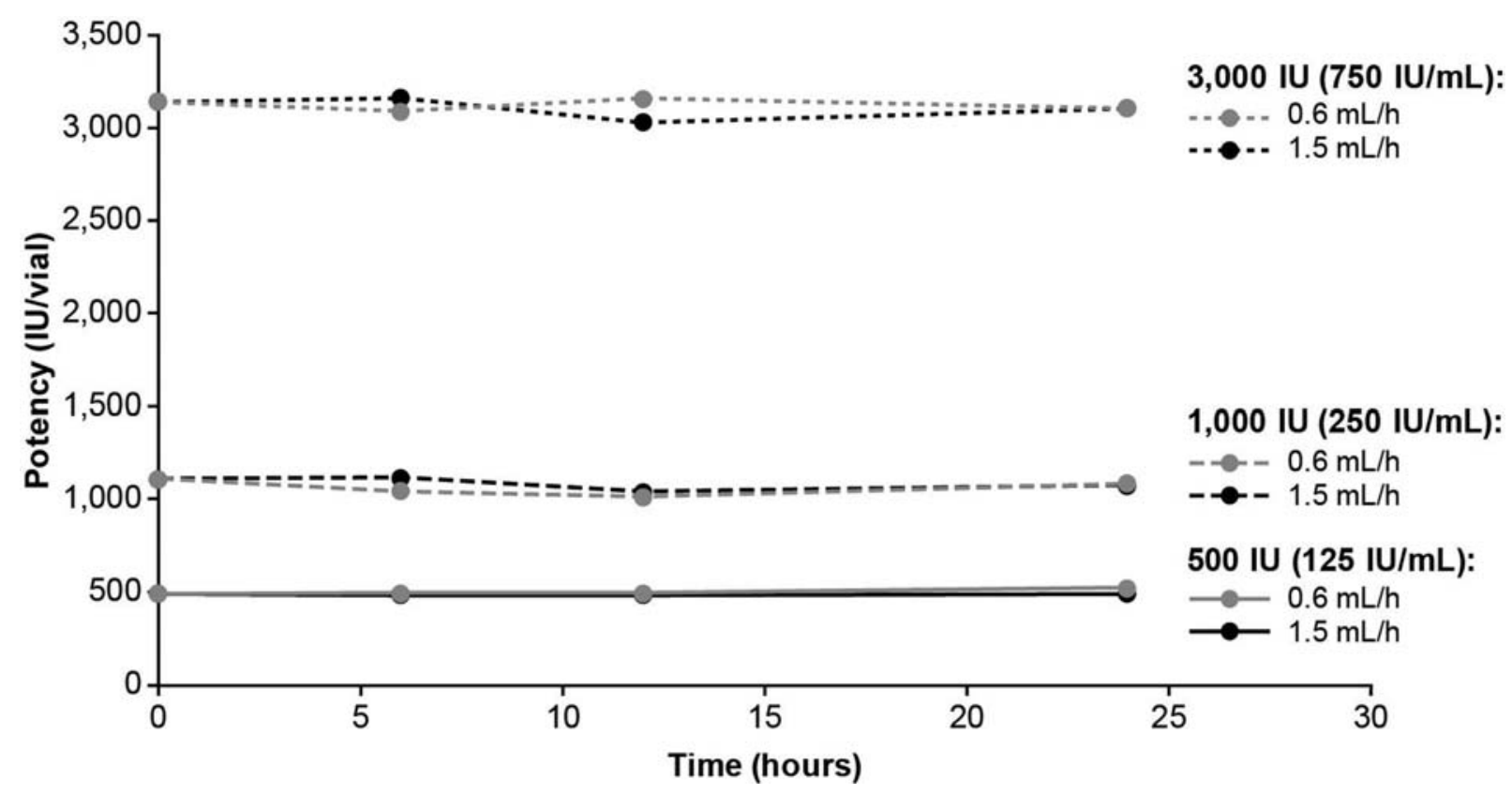

Fig. 1 Potency of turoctocog alfa assessed during 24 hours of $\mathrm{Cl}$ at pump speeds of 0.6 and $1.5 \mathrm{~mL} / \mathrm{h}$. The following turoctocog alfa samples were assessed: $500 \mathrm{IU}$ (equating to $125 \mathrm{IU} / \mathrm{mL}$ ), 1,000 IU (equating to $250 \mathrm{IU} / \mathrm{mL}$ ), and 3,000 IU (equating to $750 \mathrm{IU} / \mathrm{mL}$ ). The potency results for the test samples were all within the predefined acceptance criteria (within $20 \%$ of the mean potency of the sample of $t=0$ hours). For the $1.5 \mathrm{~mL} /$ hour pump speed, the \% difference from the mean potency at $t=0$ hours was $-1.57,-1.58$, and -0.16 for $500-\mathrm{IU}$ samples; $0.71,-5.96$, and -2.87 for $1,000-\mathrm{IU}$ samples; and 0.69 , -3.50 , and -1.12 for $3,000-\mathrm{IU}$ samples. For the $0.6 \mathrm{~mL} /$ hour pump speed, the \% difference from the mean potency at $t=0$ hours was $0.42,0.43$, and 5.99 for $500-\mathrm{IU}$ samples; $-5.72,-8.49$, and -2.15 for 1,000-IU samples; and $-1.60,0.63$, and -1.11 for 3,000-IU samples. Cl, continuous infusion.

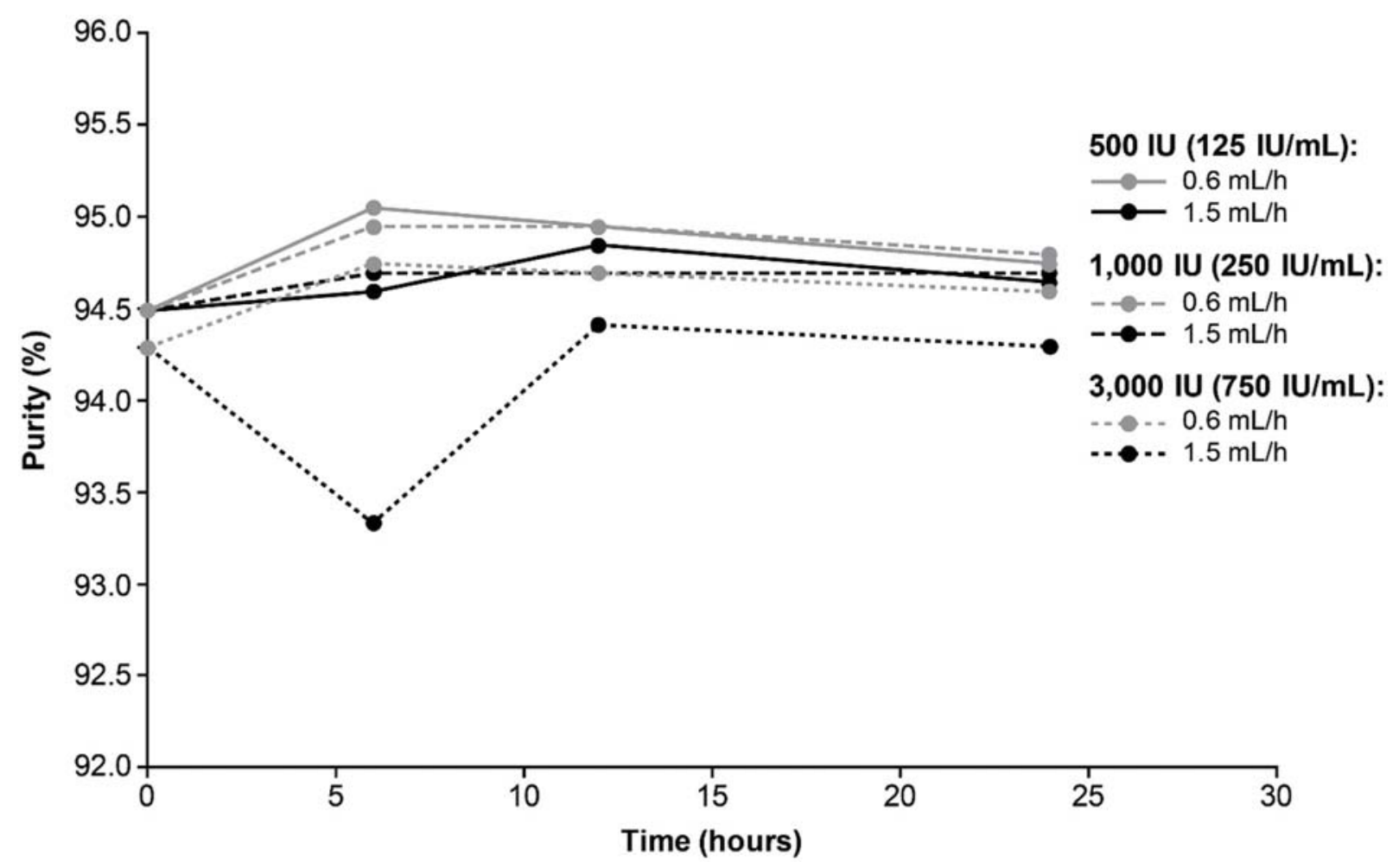

Fig. 2 Purity of turoctocog alfa assessed during 24 hours of $\mathrm{Cl}$ at pump speeds of 0.6 and $1.5 \mathrm{~mL} / \mathrm{h}$. The following turoctocog alfa samples were assessed: $500 \mathrm{IU}$ (equating to $125 \mathrm{IU} / \mathrm{mL}$ ), $1,000 \mathrm{IU}$ (equating to $250 \mathrm{IU} / \mathrm{mL}$ ), and 3,000 IU (equating to $750 \mathrm{IU} / \mathrm{mL}$ ). Cl, continuous infusion.

\section{Purity}

The purity of turoctocog alfa at $t=0$ hours was 94.4 and $94.5 \%$ for $500 \mathrm{IU}, 94.4$ and $94.5 \%$ for $1,000 \mathrm{IU}$, and $94.3 \%$ (reading obtained for both replicates) for 3,000 IU. For all strengths of turoctocog alfa and both pump speeds evaluated, the mean purity was comparable to the reference samples $(t=0)$ at 6,12 , and 24 hours of $\mathrm{CI}$ (-Fig. 2) and within predefined acceptance limits. 


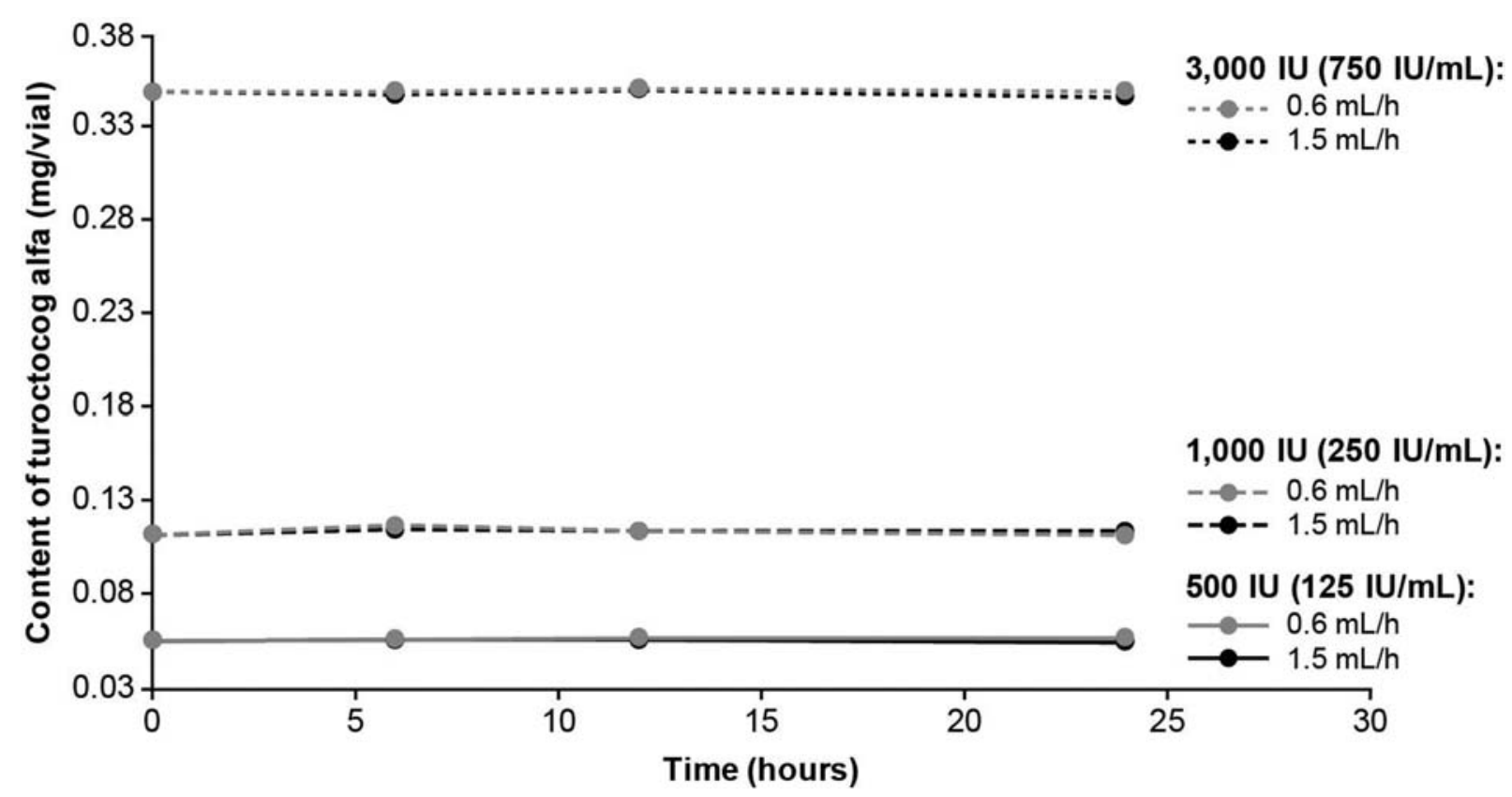

Fig. 3 Turoctocog alfa content was assessed during 24 hours of $\mathrm{Cl}$ at pump speeds of 0.6 and $1.5 \mathrm{~mL} / \mathrm{h}$. The following turoctocog alfa samples were assessed: $500 \mathrm{IU}$ (equating to $125 \mathrm{IU} / \mathrm{mL}$ ), 1,000 IU (equating to $250 \mathrm{IU} / \mathrm{mL}$ ), and 3,000 IU (equating to $750 \mathrm{IU} / \mathrm{mL}$ ). Cl, continuous infusion.

\section{Content of Turoctocog Alfa}

At $t=0$ hours, the turoctocog alfa content (mg/vial) was 0.055 and 0.056 for $500 \mathrm{IU}, 0.112$ and 0.113 for $1,000 \mathrm{IU}$, and 0.348 and 0.350 for 3,000 IU. The content of turoctocog alfa in the test samples was similar over 24 hours of $\mathrm{CI}$ for all vial strengths and both infusion speeds evaluated and within acceptance limits for shelf life (-Fig. 3 ).

\section{Total High Molecular Weight Proteins}

There were minor increases in total HMWP content over time, with the greatest increase in the 3,000-IU sample (-Fig. 4). The mean (\%) for the 3,000-IU sample at 0, 6, 12, and 24 hours infusion was $1.3,2.2,2.3$, and $2.7 \%$, for the $1.5 \mathrm{~mL} / \mathrm{h}$ pump speed, and $1.3,2.1,2.3$, and $2.8 \%$ for the $0.6 \mathrm{~mL} / \mathrm{h}$ pump speed, respectively. For all turoctocog alfa

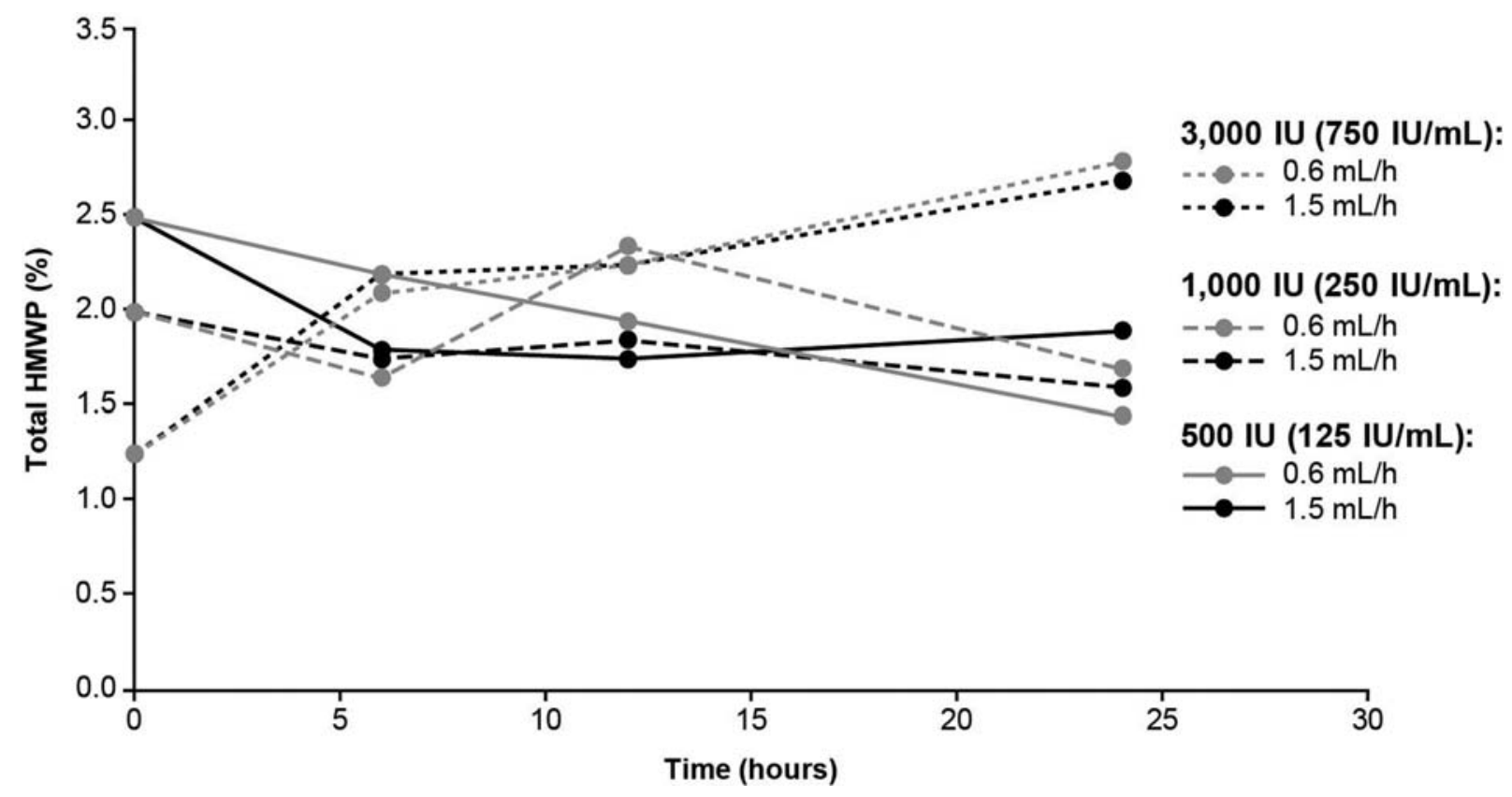

Fig. 4 The total HMWP content of turoctocog alfa was assessed during 24 hours of $\mathrm{Cl}$ at pump speeds of 0.6 and $1.5 \mathrm{~mL} / \mathrm{h}$. The following turoctocog alfa samples were assessed: $500 \mathrm{IU}$ (equating to $125 \mathrm{IU} / \mathrm{mL}$ ), $1,000 \mathrm{IU}$ (equating to $250 \mathrm{IU} / \mathrm{mL}$ ), and 3,000 IU (equating to $750 \mathrm{IU} / \mathrm{mL}$ ). $\mathrm{Cl}$, continuous infusion; HMWP, high molecular-weight protein. 


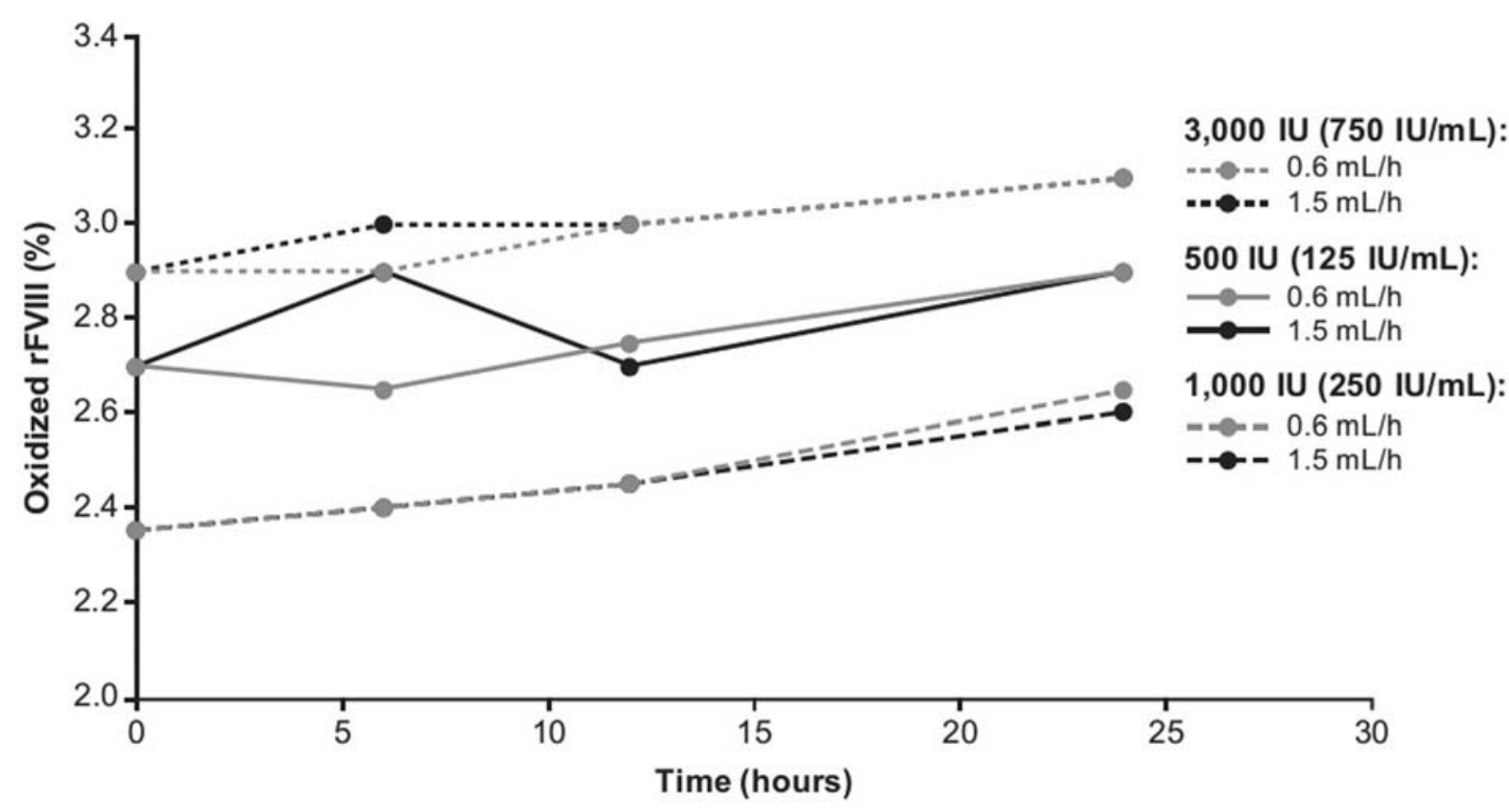

Fig. 5 Oxidized forms of turoctocog alfa were assessed during 24 hours of $\mathrm{Cl}$ at pump speeds of 0.6 and $1.5 \mathrm{~mL} / \mathrm{h}$. The following turoctocog alfa samples were assessed: $500 \mathrm{IU}$ (equating to $125 \mathrm{IU} / \mathrm{mL}$ ), 1,000 IU (equating to $250 \mathrm{IU} / \mathrm{mL}$ ), and 3,000 IU (equating to $750 \mathrm{IU} / \mathrm{mL}$ ). Cl, continuous infusion; rFVIII, recombinant factor VIII.

strengths tested, the mean total HMWP content at 6,12 , and 24 hours, for both pump speeds assessed, were comparable with the samples of $t=0$ hours $(2.5 \%$ for $500 \mathrm{IU}, 2.0 \%$ for $1,000 \mathrm{IU}$, and $1.3 \%$ for $3,000 \mathrm{IU}$ ) and within acceptance criteria for shelf life.

\section{Oxidized Forms of rFVIII}

There were small increases in oxidized forms of rFVIII over time ( - Fig. 5), but for both pump speeds evaluated, the mean values at 6,12 , and 24 hours were comparable with those from the $t=0$ hour samples $(2.7 \%$ for $500 \mathrm{IU}, 2.4 \%$ for 1,000 $\mathrm{IU}$, and $2.9 \%$ for $3,000 \mathrm{IU}$ ) and within acceptance criteria.

\section{Discussion}

A key requirement of FVIII concentrates for $\mathrm{Cl}$ is that they are stable under the conditions of administration and over the duration of administration. Stability studies have demonstrated the enhanced stability of recombinant factor products following reconstitution at room temperature, from 24 hours to 7 days. ${ }^{10,21}$ Continuous infusion has also been shown to be safe in the hospital setting and to provide a constant level of FVIII by balancing input with clearance. $^{4,6-9,14}$ Continuous infusion, therefore, provides an attractive alternative to bolus infusion, especially if replacement therapy is required for more than 3 days, for example, during surgery or severe bleeds which require hospitalization. ${ }^{14}$ Other than cost savings, ${ }^{13}$ the benefits of continuous infusion avoids peak FVIII levels which can occur in patients with comorbidities, such as age, obesity, thrombotic risk, and trough FVIII levels, associated with high bleeding risk. ${ }^{29,30}$
Here, we have shown that the chemical and physical stability of turoctocog alfa was maintained during $\mathrm{Cl}$ at $30^{\circ}$ C over 24 hours, under the conditions assessed. There was no degeneration or change in the potency, purity, or content of turoctocog alfa, and only minor increases in total HMWP and oxidized forms, across a range of turoctocog alfa strengths (500, 1,000, and 3,000 IU) equating to doses of 1.1 to 16.1 $\mathrm{IU} / \mathrm{h} / \mathrm{kg}$ of body weight. In all cases, results were similar to those of the sample of $t=0$ hours and, for potency, within the prespecified acceptance criteria.

Continuous infusion administration practices vary across centers and regions. ${ }^{13,14}$ In this study, we used three concentrations of turoctocog alfa, at a low- and high-pump speeds, using methods for $\mathrm{Cl}$ aligned with those used in clinical practice centers in Japan and the United Kingdom. It has been recommended that replacement products should not be further diluted for $\mathrm{CI}$ to avoid affecting product stability and to allow a low volume for infusion. ${ }^{14}$ However, many centers do dilute factor concentrates and report stable FVIII activity levels. ${ }^{28,31}$ In the interest of safety, it is recommended to test the stability of factor concentrates with the particular infusion set for $\mathrm{CI}^{14}$

\section{Limitations}

As this is an in vitro study, one limitation is that it cannot replicate all situations that may affect FVIII concentrate stability in the clinical setting. For example, $\mathrm{CI}$ relies on good venous access; any failure in venous access in practice may lead to a reduction in infusion time and a risk of reduced FVIII level. Furthermore, no precautions were taken during the in vitro analysis to protect the reconstituted 
turoctocog alfa solution from direct light (as advised by the manufacturer). ${ }^{17}$

\section{Conclusion}

The stability of turoctocog alfa was maintained during $\mathrm{CI}$ at $30^{\circ} \mathrm{C}$ over 24 hours, with no degradation or change in any of the chemical and physical parameters tested as per predefined acceptance criteria consistent with shelf life specifications. Particularly, the potency of turoctocog alfa was sustained throughout the 24 hours of $\mathrm{CI}$.

\section{Note}

This work was presented in abstract form at the 12th Annual Congress of the European Association for Haemophilia and Allied Disorders, Prague, Czech Republic, February 6 to 8,2019 .

\section{Authors' Contributions}

All authors contributed to analysis and/or interpretation of data, critical writing, or revising the intellectual content and final approval of the manuscript.

\section{Conflict of Interest}

M.T.'s department has been supported by funding from Novo Nordisk A/S. A.M.N. is an employee of Novo Nordisk A/S. D.P. received no payment in relation to this study but has received speaker's fees and consultation fees, as well as honoraria for advisory boards from Novo Nordisk A/S, Roche, Shire, and SOBI.

\section{Acknowledgments}

The authors wish to thank Jane Taaftegaard Jensen and Dorthe Kirstine Normann Rasmussen for the design and execution of the study. Emily Bruce (Parexel) provided drafts and editorial assistance to the authors during the preparation of this manuscript, supported by funding from Novo Nordisk A/S. Novo Nordisk's policy on data sharing may be found at: https://www.novonordisktrials.com/how-access-clinical-trial-datasets.

\section{References}

1 Chevalier Y, Dargaud Y, Lienhart A, Chamouard V, Negrier C. Seventy-two total knee arthroplasties performed in patients with haemophilia using continuous infusion. Vox Sang 2013;104(02): 135-143

2 Soucie JM, Cianfrini C, Janco RL, et al. Joint range-of-motion limitations among young males with hemophilia: prevalence and risk factors. Blood 2004;103(07):2467-2473

3 Srivastava A, Brewer AK, Mauser-Bunschoten EP, Treatment Guidelines Working Group on Behalf of The World Federation Of Hemophilia, et al. Guidelines for the management of hemophilia. Haemophilia 2013;19(01):e1-e47

4 Batorova A, Martinowitz U. Intermittent injections vs. continuous infusion of factor VIII in haemophilia patients undergoing major surgery. Br J Haematol 2000;110(03):715-720

5 Martinowitz U, Luboshitz J, Bashari D, et al. Stability, efficacy, and safety of continuously infused sucrose-formulated recombinant factor VIII (rFVIII-FS) during surgery in patients with severe haemophilia. Haemophilia 2009;15(03):676-685
6 Meijer K, Rauchensteiner S, Santagostino E, et al. Continuous infusion of recombinant factor VIII formulated with sucrose in surgery: non-interventional, observational study in patients with severe haemophilia A. Haemophilia 2015;21(01):e19-e25

7 Park YS, Shin WJ, Kim KI. Comparison of continuous infusion versus bolus injection of factor concentrates for blood management after total knee arthroplasty in patients with hemophilia. BMC Musculoskelet Disord 2017;18(01):356

8 Takedani H. Continuous infusion during total joint arthroplasty in Japanese haemophilia A patients: comparison study among two recombinants and one plasma-derived factor VIII. Haemophilia 2010;16(05):740-746

9 Takeyama M, Nogami K, Kobayashi R, et al. Continuous infusions of B domain-truncated recombinant factor VIII, turoctocog alfa, for orthopedic surgery in severe hemophilia A: first case report. Int J Hematol 2018;108(02):199-202

10 Shields S, Kim A, Elder J. Extended stability and sterility of antihemophilic factor human. J Pediatr Pharmacol Ther 2017; 22(03):203-206

11 Brand-Staufer B, Dahl PW, Johansen SD, Nøhr AM. Turoctocog alfa is stable during storage at $40^{\circ} \mathrm{C}$ and multiple sequences of temperature cycling. Abstract number: M-P-052. Presented at World Federation of Haemophilia Congress, May 20-24, 2018. Haemophilia 2018;24(S5):30

12 Fernandez M, Yu T, Bjornson E, Luu H, Spotts G. Stability of ADVATE, antihemophilic factor (recombinant) plasma/albuminfree method, during simulated continuous infusion. Blood Coagul Fibrinolysis 2006;17(03):165-171

13 Batorova A, Holme P, Gringeri A; European Haemophilia Treatment Standardisation Board, et al. Continuous infusion in haemophilia: current practice in Europe. Haemophilia 2012;18(05): 753-759

14 Holme PA, Tjønnfjord GE, Batorova A. Continuous infusion of coagulation factor concentrates during intensive treatment. Haemophilia 2018;24(01):24-32

15 New Zealand data sheet Available at: https://www.medsafe.govt. nz/profs/Datasheet/a/advateinj.pdf. Accessed October 9, 2020

16 Tiede A, Klamroth R, Oldenburg J. Turoctocog alfa (recombinant factor VIII). Manufacturing, characteristics and clinical trial results. Hamostaseologie 2015;35(04):364-371

17 NovoEight: summary of product characteristics Available at: https://www.ema.europa.-

eu/en/documents/product-information/novoeight-epar-product-information_en.pdf. Accessed October 9, 2020

18 Santagostino E, Lentz SR, Misgav M, et al. Safety and efficacy of turoctocog alfa (NovoEight) during surgery in patients with haemophilia A: results from the multinational guardian clinical trials. Haemophilia 2015;21(01):34-40

19 Kulkarni R, Karim FA, Glamocanin S, et al. Results from a large multinational clinical trial (guardian3) using prophylactic treatment with turoctocog alfa in paediatric patients with severe haemophilia A: safety, efficacy and pharmacokinetics. Haemophilia 2013;19(05):698-705

20 Lentz SR, Misgav M, Ozelo M, et al. Results from a large multinational clinical trial (guardian ${ }^{\mathrm{TM}} 1$ ) using prophylactic treatment with turoctocog alfa in adolescent and adult patients with severe haemophilia A: safety and efficacy. Haemophilia 2013;19(05): 691-697

21 Skands ARH, Engelund DK, Rossmeisl CC, Sejling K. Stability of Turoctocog Alfa, a New rFVIII Product from Novo Nordisk, When Stored at High Temperature and Humidity. Haemophilia 2014;20 (Suppl 3):176

22 International Conference on Harmonisation of Technical Requirements for Registration of Pharmaceuticals for Human Use ICH Harmonised Tripartite Guideline Quality of biotechnological products: stability testing of biotechnological/biological products. November 30, 1995. Available at: https://database.ich.org/sites/default/files/Q5C\%20Guideline.pdf. Accessed October 20, 2020 
23 European Pharmacopoeia 2.2.1 Physical and physicochemical methods Clarity and degree of opalescence of liquids Available at: https://www.drugfuture.com/Pharmacopoeia/EP7/DATA/ 20201E.PDF. Accessed January 21, 2020

24 European Pharmacopoeia 2.2.3 Potentiometric determination of pH Available at: http://www.uspbpep.com/ep50/2.2.3.\%20Potentiometric\%20determination\%20of\%20pH.pdf. Accessed January 21,2020

25 US Pharmacopeia $<791>$ pH Available at: http://www.uspbpep.com/usp29/v29240/usp29nf24s0_c791.html. Accessed November 28,2018

26 Japanese Pharmacopoeia Japanese Pharmacopoeia 17th Editionhttps://www.pmda.go.jp/english/rs-sb-std/standards-development/jp/0019.html. Accessed January 21, 2020

27 European Pharmacopoeia 2.7.4 Assay of human coagulation factor VIII Available at: https://www.biotoxik.it/wp-content/uploads/
2017/11/20704E-Assay-of-Human-Coagulation-FVIII.pdf. Accessed January 21, 2020

28 Revel-Vilk S, Blanchette VS, Schmugge M, Clark DS, Lillicrap D, Rand ML. In vitro and in vivo stability of diluted recombinant factor VIII for continuous infusion use in haemophilia A. Haemophilia 2010;16(01):72-79

29 Henrard S, Speybroeck N, Hermans C. Impact of being underweight or overweight on factor VIII dosing in hemophilia A patients. Haematologica 2013;98(09):1481-1486

30 Jenkins PV, Rawley O, Smith OP, O'Donnell JS. Elevated factor VIII levels and risk of venous thrombosis. Br J Haematol 2012;157(06): 653-663

31 Shim YJ, Lee KS, Kim UH, Suh JK, Baik SY, Hyun SY. Progress of in vitro factor VIII coagulant activity from 0 to 8 hours after reconstitution. Blood Res 2014;49(04):265-269 